\title{
EDITORIAL
}

\section{Os mestrados profissionais em ensino das ciências da natureza no Brasil}

A área de Ensino ${ }^{1}$ da Capes tem apresentado um crescimento significativo dos cursos de mestrado profissional, sendo, atualmente, o número desses cursos maior que os de mestrado acadêmico. Essa modalidade de pós-graduação pode ser atribuída à influência das políticas educacionais propostas por organismos internacionais, como a Organização de Cooperação e Desenvolvimento Econômico (OCDE) e o Banco Mundial (BM), para países centrais e periféricos, visando a adequação da educação às exigências do mercado mundial e à nova etapa de internacionalização do capitalismo. Nesta agenda, a educação em serviço é vista como a forma mais barata e eficiente de formar professores; e a melhoria da qualidade da educação é atribuída exclusivamente aos docentes por meio do desempenho escolar dos estudantes, em geral, medido por testes de grande escala.

Tais concepções encontram-se, em grande parte, naturalizadas nas políticas educacionais recentes e na literatura sobre a formação docente publicada no Brasil e em outros países, reforçando, também, a ideia de que os professores nunca estão preparados e precisam ser constantemente (re)formados e avaliados. Como consequência, em diferentes países, tem sido priorizada a prestação de contas do professor e propostas políticas que diferenciam salários de acordo com um suposto mérito mensurado por avaliações externas.

Ao ser direcionada por estas concepções, a política de implantação dos mestrados profissionais deixa de lado a questão da pouca atratividade da carreira docente. É com esta preocupação que vozes mais críticas têm apontado que toda política de formação docente deve ser integrada à estruturação da carreira, à política salarial que assegure dignidade ao professor e garantia de condições adequadas de trabalho, o que, segundo Maués (2011), não são ações visadas pela agenda da OCDE.

Assim, a política de formação continuada por meio dos mestrados profissionais não consegue reverter a carência de professores da Educação Básica por não propiciar melhorias profissionais significativas e, também, porque a maioria dos professores egressos desses cursos não permanece na escola em que lecionava, migrando para o Ensino Superior ou para os Institutos Federais de Educação, Ciência e Tecnologia (SCHÄFER, 2013). Este fenômeno, que pode ser comum a muitos cursos semelhantes no país, acaba por não só não suprir, como aumentar a carência de professores da rede pública estadual, onde se encontra a maior demanda por matrículas no Ensino Médio.

\footnotetext{
${ }^{1}$ Em 2012, foi criada a área de Ensino da CAPES, que passou a compreender a área de Ensino de Ciências e Matemática, e passou a abrigar os programas de Pós-Graduação em Ensino de todas as disciplinas.
} 
Ao mesmo tempo, as novas exigências de preparação das pessoas para um mercado mais competitivo e globalizado tem levado a formação continuada a ser mais valorizada do que a inicial (MAUÉS, 2011); e a privilegiar o conhecimento do conteúdo das matérias, considerado mais importante para o rendimento dos alunos do que o conhecimento pedagógico. Estas orientações estão em sintonia com a ênfase no conhecimento específico observada na configuração dos cursos de mestrado profissional na área de Ensino de Ciências e Matemática desde sua criação.

Há aspectos estruturais na proposta dos mestrados profissionais que deveriam ser encarados como questões para reflexão acadêmica. A escolha da universidade enquanto lócus da formação, por exemplo, é questionável. Estudos sobre as tendências atuais da formação continuada apontam para a necessidade de se eleger a escola como o lócus privilegiado de formação. Ações de formação continuada que atingem indivíduos isoladamente não trazem resultado efetivo para o contexto escolar (KUENZER, 2011). Além da necessidade de serem coletivos, os processos de formação, em parceria com a universidade, precisam ser centrados nos problemas cotidianos da escola, e não se configurarem enquanto formação academicista, pouco sintonizada com a realidade educacional.

Outro aspecto dos mestrados profissionais que merece atenção é a formação conteudista, que tem favorecido o modelo do professor especialista técnico (SOUZA, 2015). Em contrapartida, acreditamos que a formação deveria visar a um profissional capaz de refletir sobre as relações entre educação e sociedade, incluindo aspectos atuais da educação brasileira, como: as políticas curriculares, as finalidades do Ensino Médio e do ensino de ciências para a sociedade. Com essa orientação, seria adequado buscar, na escola, os problemas vigentes e moldar os referenciais teóricos e metodológicos de acordo com a natureza desses problemas.

O modelo de formação do professor especialista técnico é coerente com a exigência do desenvolvimento de produtos educacionais como parte dos trabalhos de conclusão dos mestrados profissionais, o que também reflete a tradição tecnicista da área de ensino (OSTERMANN; REZENDE, 2009). A racionalidade da utilização de recursos didáticos é a mesma que sustenta o modelo de formação do especialista técnico, na medida em que ambas se pautam pela aplicação do conhecimento especializado sem considerar os objetivos do ensino e os contextos educacionais. Entretanto, acreditamos que ainda que não sejam concebidos nesta lógica, sendo elaborados por um determinado professor para uma escola em particular, os produtos educacionais não representariam solução para os problemas da educação brasileira, que são muito mais complexos e envolvem questões de outra natureza. Além disso, conforme levantamento realizado por Rezende, Ostermann e Ferraz (2009), a produção nacional sobre o ensino de física, por exemplo, já é abundante de propostas de metodologias de ensino, desenvolvimento de experimentos para o laboratório didático e elaboração de materiais didáticos para a sala de aula, o que vem a tornar a produção dos mestrados profissionais como "mais do mesmo".

Neste cenário, vemos como oportuna a ideia de repensar os cursos de mestrado profissional, posicionando-os criticamente em relação ao modelo do especialista técnico, buscando privilegiar outros modelos formativos e uma variedade de discursos que poderiam arejar as disciplinas, as discussões sobre as finalidades do curso e sobre os trabalhos de conclusão a serem elaborados pelos professores. Assim, defendemos que as ideias trazidas aqui sejam vistas como objeto de reflexão de todos os atores envolvidos na formação continuada de professores. Essa discussão já vem tomando forma no âmbito de um projeto de pesquisa em rede iniciado em 2013, do qual fazemos parte, financiado pelo Edital Observatório da Educação da CAPES. 
Esse projeto inclui: pesquisadores, alunos de pós-graduação, de graduação e professores da Educação Básica mobilizados pelas reflexões empreendidas e entusiasmados com a possibilidade de contribuir para a transformação das práticas de formação docente.

Fernanda Ostermann Departamento de Física, Instituto de Física, Universidade Federal do Rio Grande do Sul (UFRGS), Campus do Vale, Caixa Postal 15051, 91501-970, Porto Alegre, RS, Brasil. E-mail: fernanda.ostermann@ufrgs.br

Flávia Rezende Programa de Pós-Graduação em Ensino de Física, Instituto de Física, UFRGS. E-mail: flaviarezende@uol.com.br

\section{Referências}

KUENZER, A. Z. A formação de professores para o ensino médio: velhos problemas, novos desafios. Educação \& Sociedade, Campinas, v. 32, n. 116, p. 667-688, 2011.

MAUÉS, O. C. A política da OCDE para a educação e a formação docente. A nova regulação? Educação, Porto Alegre, v. 34, n. 1, p. 75-85, 2011.

OSTERMANN, F.; REZENDE, F. Projetos de desenvolvimento e de pesquisa na área de ensino de ciências e matemática: uma reflexão sobre os mestrados profissionais. Caderno Brasileiro de Ensino de Física, Florianópolis, v. 26, n. 1, p. 66-80, 2009.

REZENDE, F.; OSTERMANN, F.; FERRAZ, G. Ensinoaprendizagem de física no nível médio: o estado da arte da produção acadêmica no século XXI. Revista Brasileira de Ensino de Física, São Paulo, v. 31, n. 1, p. 1402-1-1402-8, 2009.

SCHÄFER, E. D. A. Impacto do mestrado profissional em ensino de física da UFRGS na prática docente: um estudo de caso. 2013. Tese (Doutorado em Ensino de Física) - Instituto de Física, Universidade Federal do Rio Grande do Sul, Porto Alegre, 2013.

SOUZA, J. de. Apropriação discursiva de modelos de formação docente em trabalhos de conclusão de um mestrado profissional em ensino de física. 2015. Dissertação (Mestrado Acadêmico em Ensino de Física) - Instituto de Física, Universidade Federal do Rio Grande do Sul, Porto Alegre, 2015. 